\title{
On-capillary complexation of metal ions with 4-(2-thiazolylazo)resorcinol in capillary electrophoresis
}

\author{
Min Wang ${ }^{\mathrm{a}}$, Jin-Ming Lin ${ }^{\mathrm{a}, *}$, Feng Qu $^{\mathrm{a}}$, Xiaoquan Shan ${ }^{\mathrm{a}}$, Zuliang Chen ${ }^{\mathrm{b}}$ \\ ${ }^{a}$ Research Center for Eco-Environmental Sciences, Chinese Academy of Sciences, P.O. Box 2871, Beijing 100085, China \\ ${ }^{\mathrm{b}}$ Center for Environmental Risk Assessment and Remediation, University of South Australia, Mawson Lakes, SA 5095, Australia
}

Received 4 August 2003; received in revised form 9 December 2003; accepted 9 December 2003

\begin{abstract}
$\mathrm{Co}(\mathrm{II}), \mathrm{Zn}(\mathrm{II}), \mathrm{Ni}(\mathrm{II})$ and $\mathrm{Fe}(\mathrm{II})$ were successfully separated by capillary electrophoresis using pre-capillary and on-capillary complexation with 4-(2-thiazolylazo)resorcinol. The influences of some crucial parameters, including both pre- and on-capillary complexation procedure, were investigated. For on-capillary complexation, the complexing reaction was carried out inside the capillary by mixing the zones of ligand and sample during the electrophoretic migration. Compared with pre-capillary complexation, the method provided 30-fold reduction in detection limits for $\mathrm{Co}$ (II), 50-fold reduction for $\mathrm{Zn}$ (II), and 100-fold reduction for $\mathrm{Ni}$ (II) and $\mathrm{Fe}(\mathrm{II})$. It was used for the analysis of a pharmaceutical and tap water sample.
\end{abstract}

(c) 2004 Elsevier B.V. All rights reserved.

Keywords: Complexation; Metal cations; Thiazolylazoresorcinol; Transition metals

\section{Introduction}

Transition metals are among the most important elements in environmental analysis due to their potential roles in plant and animal bioactivity. These roles of transition metals in the environment depend on their concentration in the soil, water and living things. Thus, sensitive and rapid methods are needed to determine the qualitative and quantitative composition of these possible metal sources. Atomic absorption spectrometry is the most widely used method. However, it does suffer a drawback in that simultaneous multi-element analysis is not possible. The separation and determination of metal ions with conventional high-performance liquid chromatography (HPLC) and ion-chromatography (IC) still exhibit several disadvantages, such as long analysis times, large consumption of eluent and high costs for special column hardware.

During recent years, capillary electrophoresis (CE) has become a recognized and useful technology in the area of metal analysis. A distinct feature of the separation of metal ions by $\mathrm{CE}$ is the frequent use of complexing ligands to

\footnotetext{
* Corresponding author. Tel.: +86-10-6284-1953; fax: +86-10-6284-1953.

E-mail address: jmlin@mail.rcees.ac.cn (J.-M. Lin).
}

form complexes that either manipulate separation selectivity or facilitate their detection. Many complexing ligands, such as 8-hydroxyquinoline-5-sulfonic acid (HQS) [1,2], 1,10-phenanthroline [3,4], 2-hydroxyisobutyric acid (HIBA) [5,6] and 4-(2-pyridylazo)resorcinol (PAR) [7,8] have been applied to CE separation.

Thiazolyazo reagents, like 4-(2-thiazolylazo)resorcinol (TAR), are popular as metal complexing ligands in spectrophotometry [9], HPLC [10] and IC [11] due to the advantages that they can form highly sensitive metal complexes, and are very easily synthesized and purified. However, they are still seldom utilized in CE separations. Saitoh et al. [12] reported the determination of partition constant of complexes of $\mathrm{Fe}$ (II) with thiazolyazo reagents into SDS micelle by micellar electrokinetic capillary chromatography (MECC). Liu et al. [13] demonstrated an excellent separation of Co(II) and rare earth metal ions as their TAR complexes by $\mathrm{CE}$ and investigated the influence of organic additivies on the separation. Evans and Collins [14] developed a capillary zone electrophoresis (CZE) method for the analysis of $\mathrm{U}(\mathrm{VI})$ and transition metal ions utilizing TAR. More recently, we reported the separation of $\mathrm{Co}(\mathrm{II}), \mathrm{Zn}(\mathrm{II})$, $\mathrm{Ni}(\mathrm{II})$ and $\mathrm{Fe}(\mathrm{II})$ with TAR by CZE [15]. Compared with PAR, TAR is much better suited for the CE separation of metal ions in the absence of a surfactant, and in slight acidic 
or natural solutions [14]. Except for these three papers, to our knowledge, no other report concerning the separation of metal-TAR complexes by CE has been published.

Whether pre- or on-capillary complexation is used, the primary consideration is the kinetics of metal-TAR complexes formation and dissociation. In all previous examples utilizing TAR, pre-capillary complexation has been used. However, the pre-complexation method provides poor limits of detection, as the excessive ligand in the sample increase the noise of baseline. Moreover, if small sample volumes do not allow the pre-capillary reactions, the on-capillary copmplexation method must be used. Regan et al. [16] tried a three-step on-column complexation method to separate metal ions using PAR as the complexing ligand. Haumann and Bächmann [17] proposed a new approach to realize the on-column chelation of metal ions with EDTA. These two methods require the introduction of a ligand plug into the capillary allowing the complexation reaction to occur during the contact time of the ligand zone and the sample zone. These studies have proven that the employment of a ligand plug can substantially improve detection sensitivity.

This paper investigated the detection and separation of transition metal ions with TAR using pre-capillary and on-capillary complexation by CE. The influences of some crucial parameters, including both pre- and on-capillary complexation procedure, were discussed. The applicability of the pre-capillary and on-capillary methods was demonstrated by the analysis of a pharmaceutical and tap water sample.

\section{Experimental}

\subsection{Instrumentation}

All experiments were performed on a Beckman P/ACE MDQ capillary electrophoresis system (Beckman, Fullerton, CA, USA) equipped with a photodiode array detection system. The electropherograms were recorded and integrated by an IBM personal computer with 32 Karat software version 4.0 (Beckman). A fused-silica capillary (Beckman) with a total length of $57 \mathrm{~cm}$ and an i.d. of $75 \mu \mathrm{m}$ was used. A detection window was created at $50 \mathrm{~cm}$ from the capillary inlet by removing the polyimide coating. Direct UV detection was performed at a single wavelenghth of $510 \mathrm{~nm}$ or scanning mode (190-600 nm).

\subsection{Chemicals}

TAR was purchased from Kanto (Tokyo, Japan). A $1 \times 10^{-2} \mathrm{M}$ stock solution of TAR was prepared in ethanol. The $500 \mu \mathrm{g} / \mathrm{ml}$ stock solution of metal ions, including $\mathrm{Cu}(\mathrm{II}), \mathrm{Cd}(\mathrm{II}), \mathrm{Co}(\mathrm{II}), \mathrm{Zn}(\mathrm{II}), \mathrm{Ni}(\mathrm{II})$ and $\mathrm{Fe}(\mathrm{II})$, were prepared from $\mathrm{CuSO}_{4} \cdot 5 \mathrm{H}_{2} \mathrm{O}, \mathrm{CdCl}_{2} \cdot 2.5 \mathrm{H}_{2} \mathrm{O}, \mathrm{CoSO}_{4} \cdot 7 \mathrm{H}_{2} \mathrm{O}$, $\mathrm{ZnSO}_{4} \cdot 7 \mathrm{H}_{2} \mathrm{O}, \mathrm{NiSO}_{4} \cdot 6 \mathrm{H}_{2} \mathrm{O}$ and $\mathrm{FeSO}_{4} \cdot 7 \mathrm{H}_{2} \mathrm{O}$, which were from Beijing Reagent (China), by dissolving them into water. $\mathrm{NaH}_{2} \mathrm{PO}_{4}, \mathrm{Na}_{2} \mathrm{HPO}_{4}, \mathrm{Na}_{2} \mathrm{~B}_{4} \mathrm{O}_{7}$ and Tris(hydroxymethyl)aminomethane (Tris) were also purchased from Beijing Reagent. All chemicals were of analytical grade. Water for preparation of sample and buffer solution was deionized by a easypure ${ }^{\mathrm{TM}} \mathrm{LF}$ purification system with a $0.2 \mu \mathrm{m}$ fiber filter (Barnstead, USA).

\subsection{Procedure}

New capillary was initially washed with methanol for $5 \mathrm{~min}$, followed by deionized water for $2 \mathrm{~min}, 0.1 \mathrm{M} \mathrm{HCl}$ for $5 \mathrm{~min}$, deionized water for $2 \mathrm{~min}, 0.1 \mathrm{M} \mathrm{NaOH}$ for $5 \mathrm{~min}$ and deionized water for $2 \mathrm{~min}$. To achieve reproducible separations, all experiments were performed at $25^{\circ} \mathrm{C}$ and were run in triplicate. Before each separation, the capillary was rinsed with $0.1 \mathrm{M} \mathrm{NaOH}$ for $2 \mathrm{~min}$, deionized water for $2 \mathrm{~min}$ and run buffer for $2 \mathrm{~min}$.

The optimal electrophoretic run buffer was $10 \mathrm{mM}$ Tris-HCl containing $0.1 \mathrm{mM}$ TAR. $0.1 \mathrm{M} \mathrm{HCl}$ was used to adjust buffer $\mathrm{pH}$ to 7.7 . Pre-capillary ligand-metal complexation was achieved by mixing the metal ion and appropriate amounts of TAR directly at room temperature before injection. $8.00 \mathrm{ml}$ of sample solution were diluted to $10.00 \mathrm{ml}$ using $10 \mathrm{mM}$ Tris- $\mathrm{HCl}$, and $1 \mathrm{mM}$ TAR was added. The separation voltage was $25 \mathrm{kV}$, and the injection was performed at $0.5 \mathrm{psi}$ for $5 \mathrm{~s}(1 \mathrm{psi}=6894.76 \mathrm{~Pa})$. For on-capillary complexation, a $1 \mathrm{mM}$ TAR solution was introduced into the capillary at $10 \mathrm{kV}$ for $10 \mathrm{~s}$, and then the metal ions were injected electrokinetically for $15 \mathrm{~s}$ at $10 \mathrm{kV}$. Each end of the capillary was placed into the run buffer, and a low voltage $(10 \mathrm{kV})$ was applied for $10 \mathrm{~s}$. Finally, the voltage was ramped to $25 \mathrm{kV}$ for CE separation of the complexes.

\section{Results and discussions}

\subsection{UV-Vis spectrometry}

As shown in Fig. 1, TAR is a structural analogue of PAR, the widely used metal complexation ligand in CE, with the difference being the replacement of the pyridylazo moiety with a thiazolylazo moiety. TAR can react with many transition metals, such as $\mathrm{Cu}(\mathrm{II}), \mathrm{Co}(\mathrm{II}), \mathrm{Fe}(\mathrm{II}), \mathrm{Ni}(\mathrm{II})$, and $\mathrm{Zn}$ (II) etc., and form stable and sensitive complexes of the type ML or $\mathrm{ML}_{2}$, where $\mathrm{M}$ stands for metal and $\mathrm{L}$ for ligand. These species are generally highly hydrophobic at room temperature in weakly alkaline media [9]. The stability constants of TAR metal complexes are given in Table 1. Nevertheless,

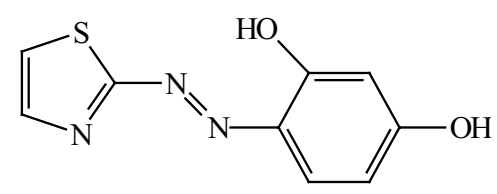

Fig. 1. The chemical structure of 4-(2-thiazolylazo)resorcinol (TAR). 
Table 1

Spectrometric data and stability constants of the metal complexes

\begin{tabular}{llllc}
\hline & $\lambda_{\mathrm{Max}^{\mathrm{a}}}$ & $\varepsilon\left(\times 10^{4} 1 / \mathrm{molcm}\right)^{\mathrm{a}}$ & $\log K_{\mathrm{ML}}{ }^{\mathrm{b}}$ & $\log K_{\mathrm{ML2}}{ }^{\mathrm{b}}$ \\
\hline $\mathrm{TAR}$ & 472 & 3.0 & - & - \\
$\mathrm{Cu}(\mathrm{II})$ & 505 & 3.1 & 12.3 & 9.9 \\
$\mathrm{Co}(\mathrm{II})$ & 508 & 3.1 & 12.05 & 11.23 \\
$\mathrm{Cd}(\mathrm{II})$ & 505 & 3.3 & 6.96 & - \\
$\mathrm{Fe}(\mathrm{II})$ & 501 & 2.1 & - & $\beta_{2} 21.6$ \\
$\mathrm{Ni}(\mathrm{II})$ & 502 & 3.3 & 12.94 & 11.82 \\
$\mathrm{Zn}$ (II) & 506 & 3.7 & 11.08 & 10.10 \\
\hline
\end{tabular}

a Determined by UV-Vis spectrometry in phosphate buffer at $\mathrm{pH} 8.0$.

b Cited from ref. [9].

little attention has been given to its application as a derivatization ligand of metals in CE.

Table 1 gives the spectrometric data in phosphate buffer at $\mathrm{pH}$ 8.0. TAR have an absorption maximum at $472 \mathrm{~nm}$, and most metal complexes of TAR show absorption maxima at wavelengths from 500 to $510 \mathrm{~nm}$, where the molar absorptivities are about $10^{4} 1 / \mathrm{mol} \mathrm{cm}$. In this work, detection was carried out at $510 \mathrm{~nm}$, where most metal-TAR complexes examined showed relatively high absorption.

\subsection{Separation of metal ions using pre-capillary complexation}

Three buffers, including phosphate, borate and Tris, were investigated for CE separation of the metal-TAR complexes. Four metals, including $\mathrm{Co}(\mathrm{II}), \mathrm{Fe}(\mathrm{II}), \mathrm{Ni}(\mathrm{II})$, and $\mathrm{Zn}(\mathrm{II})$ could be successfully separated using these buffers. However, higher separation currents $(>60 \mu \mathrm{A})$ were evident with the use of phosphate and borate buffers. Tris- $\mathrm{HCl}$ buffer exhibited much smaller separation current (15 $\mu$ A). Small current is more advantageous to $\mathrm{CE}$ separation. Consequently, Tris- $\mathrm{HCl}$ buffer was chosen for further investigations.

Higher concentration of electrophoretic run buffer reduces the $\zeta$ potential, electrical double layer and EOF, thus increasing the separation efficiency and resolution of metals. However, increasing the concentration of electrophoretic run buffer leads to larger currents, which broaden the peaks and decrease separation efficiency. It was suggested that $10 \mathrm{mM}$ Tris- $\mathrm{HCl}$ would result in an optimum separation of the metal ions.

The kinetic ability of metal complexes is a common problem in the CE analysis of metals. It is generally dealt with the addition of the complexing agent in low concentration to the buffer, in order to prevent the dissociation of the metal complexes during the migration and maintain their detectability. A lack of TAR in the electrophoretic run buffer significantly reduced the resolution of the iron and zinc complexes. High concentration of TAR, however, would increase the baseline noise and decrease the detection limits of metals [15]. So, the optimal concentration of TAR was concluded to be $0.1 \mathrm{mM}$.

The $\mathrm{pH}$ is a crucial parameter in the CE separation of metal ions, as it not only influences the EOF, but also the

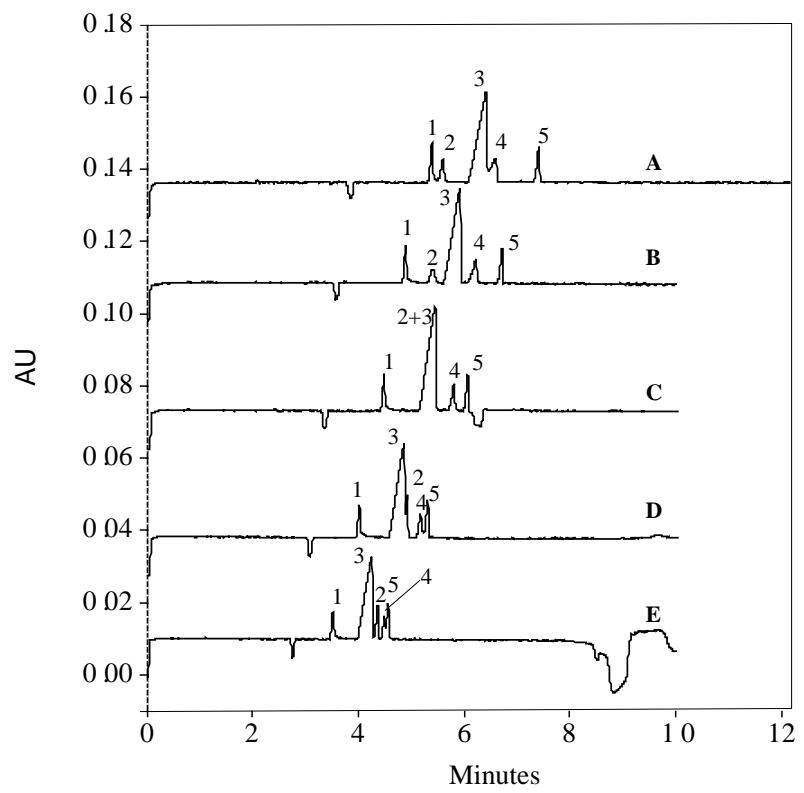

Fig. 2. Investigation of the effect of $\mathrm{pH}$ on metal ion separation using pre-capillary complexation. Conditions: buffer $10 \mathrm{mM}$ Tris- $\mathrm{HCl}$ containing $0.1 \mathrm{mM}$ TAR; voltage: $25 \mathrm{kV}$; detection $510 \mathrm{~nm}$; hydrodynamic injection $0.5 \mathrm{psi}$ for $5 \mathrm{~s}$. (A) $\mathrm{pH} 7.4$, (B) $\mathrm{pH} 7.7$, (C) $\mathrm{pH} 8.0$, (D) $\mathrm{pH} 8.3$, (E) pH 8.6. 1 , Co(II) $(1 \mu \mathrm{g} / \mathrm{ml}) ; 2, \mathrm{Fe}(\mathrm{II})(2.5 \mu \mathrm{g} / \mathrm{ml}) ; 3$, free TAR; $4, \mathrm{Zn}(\mathrm{II})$ $(1 \mu \mathrm{g} / \mathrm{ml}) ; 5, \mathrm{Ni}(\mathrm{II})(1 \mu \mathrm{g} / \mathrm{ml})$.

acid dissociation equilibria of the metal-TAR complexes. The effect of $\mathrm{pH}$ is illustrated in Fig. 2. With increasing $\mathrm{pH}$, as shown in Fig. $2 \mathrm{~A}$ to $\mathrm{E}$, the migration time of the complexes decrease due to the enhancement of the EOF. At pH 7.7, a completely baseline separation of four metal ions can be achieved. Thus, all run buffers were adjusted to $\mathrm{pH}$ 7.7 for subsequent studies.

Separation of the metal complexes was optimized in a $10 \mathrm{mM}$ Tris- $\mathrm{HCl}$ buffer $(\mathrm{pH} 7.7)$ containing $0.1 \mathrm{mM}$ TAR. Fig. 2B illustrates an electropherogram of separation of $\mathrm{Co}(\mathrm{II}), \mathrm{Fe}(\mathrm{II}), \mathrm{Ni}(\mathrm{II})$, and $\mathrm{Zn}(\mathrm{II})$ complexes following pre-capillary complexation.

\subsection{On-capillary complexation}

Whether pre- or on-capillary complexation is used, the primary consideration is the kinetics of the complexation equilibria. Excessive TAR must be added to the solution of metal ions to guarantee the complete complexation of metal ions with TAR before capillary electrophoretic separation. The pre-capillary complexation method provided poor limits of detection, ranging from 44 to $152 \mathrm{ng} / \mathrm{ml}$. It was unsuitable for the analysis of trace metals in real samples, especially environmental samples.

To improve the poor sensitivity of pre-capillary complexation, a novel on-capillary complexation method is used. The steps and mechanism involved are depicted in Fig. 3. After the washing procedure, the capillary is filled with the electrophoretic run buffer (BGS). Then, an initial plug of 


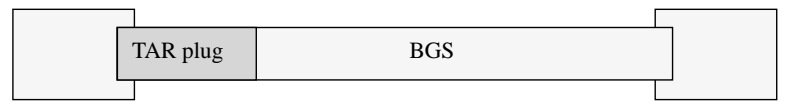

(A)

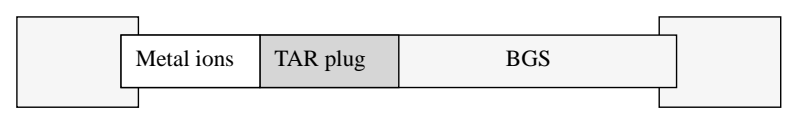

(B)
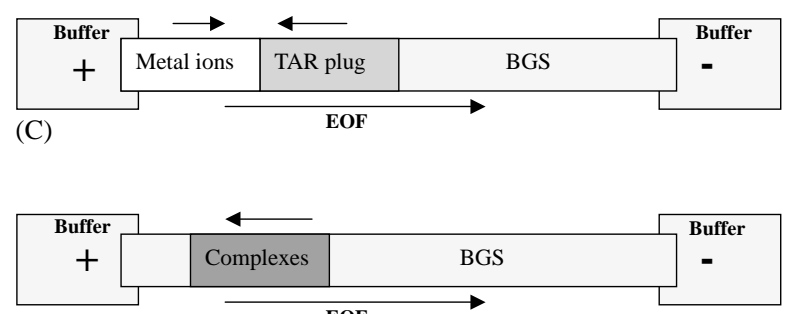

(D)

Fig. 3. Mechanism for on-capillary complexation with TAR as a complexing ligand. (A) Introduction of TAR plug. (B) Injection of metal ions. (C) On-capillary complexation of metal ions and TAR. (D) Electrophoretic separation of metal complexes.

higher concentration TAR in buffer is introduced (Fig. 3A), followed by a plug of metal ions in water (Fig. 3B), and a low voltage electric field $(10 \mathrm{kV})$ is applied (Fig. 3C). Under the selected conditions, TAR is negatively charged and its migration velocity is lower than that of positively charged metal ions; the two zones will mix together, and a complexation reaction occurs. Furthermore, TAR is prepared in the buffer solution and the metal ions are dissolved in water. The conductivity of the water solution is lower than that of the buffer. When the voltage is applied, the lower conductivity of the water results in a higher electric field. The metal ions in water will move faster than those in buffer. As metal ions reach the boundary of TAR zone and sample zone, they slow down and stack into a narrow zone. The concentration enhancement and complexation are achieved simultaneously. Finally, the voltage is ramped to $25 \mathrm{kV}$ for CE separation of the complexes (Fig. 3D).

The necessity of a TAR plug is illustrated in Fig. 4. If no plug of TAR is introduced prior to the metal ions, the peak intensities are dramatically reduced, along with significantly decreased resolution (Fig. 4A). As shown in Fig. 4B, a satisfactory $\mathrm{CE}$ separation of four metal complexes can be accomplished when an initial plug of higher concentration TAR is introduced before injection of the metal ions.

The peak areas of metal ions increased with varying the injection voltage from 2.5 to $10 \mathrm{kV}$. But higher voltage gave worse linearity because the electric field being influenced by the sample conductivity affected the calibration curve. So, the injection voltage of $10 \mathrm{kV}$ was chosen. As can be seen in Fig. 5, peak areas increase with an increase in the TAR injection time until a maximum is reached at $10 \mathrm{~s}$. Similarly, peak areas increase when varying the injection time of metal ions from 5 to $15 \mathrm{~s}$. Above this period, excess water solvent is introduced, resulting in a reduction in the resolution of the complexes.

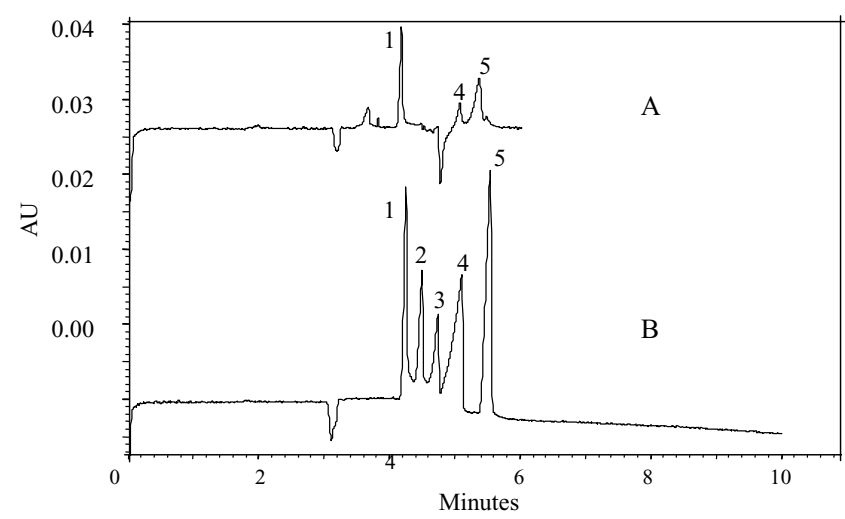

Fig. 4. Effect of TAR plug on the separation of complexes. (A) No TAR plug is introduced. (B) Introduction of TAR plug before the injection of metal ions. Conditions: electrokinetic injection of TAR, $t_{\mathrm{inj}}=10 \mathrm{~s}$, $V_{\text {inj }}=10 \mathrm{kV}$; for metal ions, $t_{\text {inj }}=5 \mathrm{~s}, V_{\mathrm{inj}}=10 \mathrm{kV}$; complexation procedure, $10 \mathrm{kV}$ for $15 \mathrm{~s}$, other conditions are the same as in Fig. 2. 1, Co(II) (100 ng/ml); 2, Fe(II) (100 ng/ml); 3, free TAR; 4, Zn(II) $(100 \mathrm{ng} / \mathrm{ml}) ; 5$, $\mathrm{Ni}(\mathrm{II})(100 \mathrm{ng} / \mathrm{ml})$.

Fig. 6 shows the results for varying the timing of the complexation process, which occurs during the application of $10 \mathrm{kV}$ to the capillary when it contained both the TAR and metal ions plugs. When the complexation time is $5 \mathrm{~s}$, the complexation of metal ions with TAR is incomplete. On the other hand, long complexation times reduce the peak areas of the metal complexes. The complexation time of $10 \mathrm{~s}$ was determined to be optimal.

\subsection{Validation}

As shown in Table 2, calibration curves for four metal complexes show linear dynamic ranges from 1 to $100 \mathrm{ng} / \mathrm{ml}$. The correlation coefficients of all metals are higher than 0.99. Relative standard deviation (R.S.D.) of peak area is calculated based on five duplicate injections of a standard

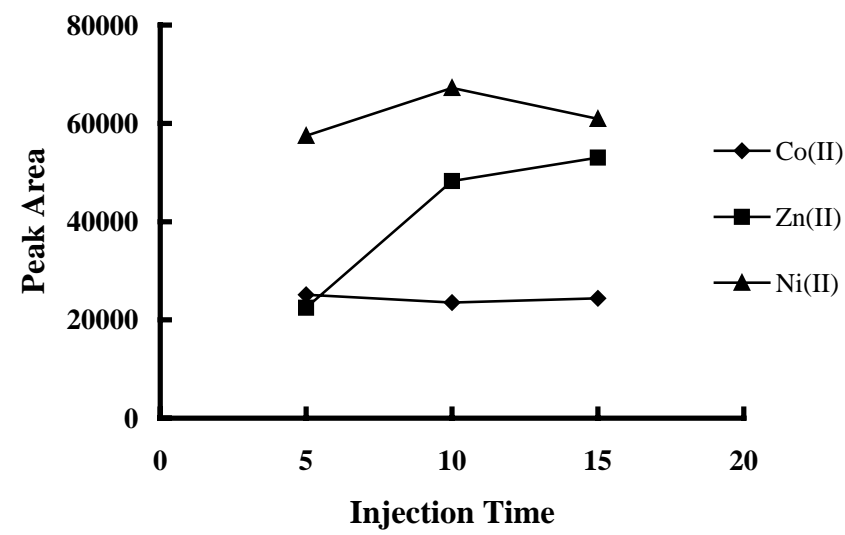

Fig. 5. Optimization of TAR injection time. Conditions: electrokinetic injection for TAR, $V_{\mathrm{inj}}=10 \mathrm{kV}$; for metal ions, $t_{\mathrm{inj}}=15 \mathrm{~s}, V_{\mathrm{inj}}=10 \mathrm{kV}$; complexation procedure, $10 \mathrm{kV}$ for $15 \mathrm{~s}$, other conditions are the same as in Fig. 2. Co(II) $(10 \mathrm{ng} / \mathrm{ml}), \mathrm{Zn}$ (II) $(20 \mathrm{ng} / \mathrm{ml}), \mathrm{Ni}(\mathrm{II})(20 \mathrm{ng} / \mathrm{ml})$. Time scale in $\mathrm{s}$. 


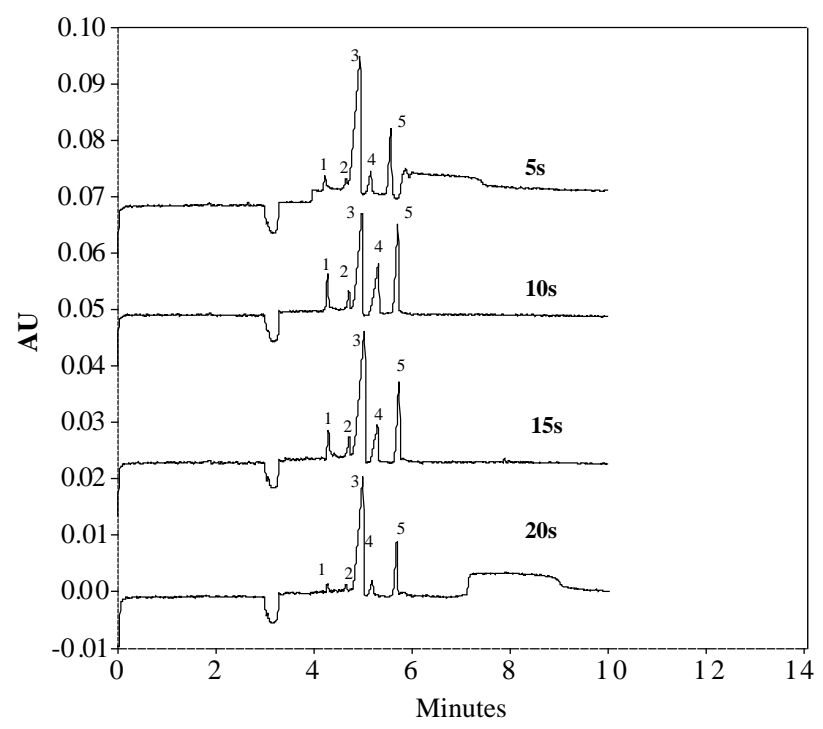

Fig. 6. Investigation of the effect of complexation time on metal ions separation. Conditions: electrokinetic injection for TAR, $t_{\text {inj }}=10 \mathrm{~s}$, $V_{\text {inj }}=10 \mathrm{kV}$; for metal ions, $t_{\text {inj }}=15 \mathrm{~s}, V_{\text {inj }}=10 \mathrm{kV}$; complexation voltage of $10 \mathrm{kV}$ is applied for varying time intervals; other conditions are the same as in Fig. 2. 1, Co(II) $(10 \mathrm{ng} / \mathrm{ml}) ; 2, \mathrm{Fe}(\mathrm{II})(20 \mathrm{ng} / \mathrm{ml}) ; 3$, free TAR; 4, Zn(II) $(10 \mathrm{ng} / \mathrm{ml}) ; 5$, Ni(II) $(10 \mathrm{ng} / \mathrm{ml})$.

Table 2

Quantification data

\begin{tabular}{lccll}
\hline Metal & $a$ & $b$ & $r$ & $\begin{array}{l}\text { Linear range } \\
(\mathrm{ng} / \mathrm{ml})\end{array}$ \\
\hline $\mathrm{Zn}(\mathrm{II})$ & 2434.3 & 1215.2 & 0.9983 & $2-100$ \\
$\mathrm{Ni}(\mathrm{II})$ & 3223.5 & 1159.1 & 0.9982 & $1-100$ \\
$\mathrm{Co}(\mathrm{II})$ & 2492.8 & -3192.6 & 0.9981 & $2-100$ \\
$\mathrm{Fe}(\mathrm{II})$ & 504.26 & 549.39 & 0.9969 & $2-100$ \\
\hline
\end{tabular}

Calibration curves are expressed as regression lines $(y=a x+b)$, where $y$ is integrated peak area and $x$ is concentration of metal ions ( $\mathrm{ng} / \mathrm{ml}) . a$ is slope, $b$ is intercept and $r$ is relative coefficient.

sample, and the values are given in Table 3 . Table 3 also gives the limits of detection (LOD) using pre- and on-capillary complexation methods, which were measured when the ratio of signal-to-noise $(\mathrm{S} / \mathrm{N})$ is 3 . Compared with pre-capillary complexation, the on-capillary method results in 30-fold reduction in detection limits for $\mathrm{Co}(\mathrm{II})$, 50-fold reduction for $\mathrm{Zn}$ (II), and 100-fold reduction for Ni(II) and Fe(II). For sim-

Table 3

The limits of detection (LOD) ( $/ \mathrm{N}=3$ ) using pre- and on-capillary complexation

\begin{tabular}{lcllll}
\hline \multirow{2}{*}{ Metal } & \multicolumn{2}{l}{ Pre-capillary complexation } & & \multicolumn{2}{c}{ On-capillary complexation } \\
\cline { 2 - 3 } \cline { 5 - 6 } \cline { 5 - 6 } & LOD (ng/ml) & R.S.D. (\%) & & LOD (ng/ml) & R.S.D. (\%) \\
\hline Zn(II) & 44 & 1.5 & & 0.7 & 0.9 \\
Ni(II) & 42 & 2.0 & & 0.4 & 0.7 \\
Co(II) & 27 & 2.2 & & 0.8 & 1.8 \\
Fe(II) & 152 & 3.1 & & 1.5 & 1.4 \\
\hline
\end{tabular}

R.S.D. is relative standard deviation $(n=5)$. ilar on-capillary complexation method, if EDTA is used as the complexing ligand, its LOD is 100-200-fold higher than LOD using TAR [17]. If PAR is used as the complexing ligand, the LOD is as the same grade [16].

\subsection{Sample analysis}

\subsubsection{Zinc gluconate solution}

A commercial zinc gluconate solution was purchased from a local pharmacy. The determination of $\mathrm{Zn}(\mathrm{II})$ in zinc gluconate solution was performed by pre- and on-capillary complexation methods, respectively. The zinc gluconate solution was diluted 250 -fold for pre-capillary complexation, and 5000-fold for on-capillary complexation, and filtered through a $0.45 \mu \mathrm{m}$ filter membrane. The electropherograms are shown in Fig. 7, and the content of $\mathrm{Zn}$ (II) determined by pre-capillary complexation was $4.0 \mathrm{mg} / 10 \mathrm{ml}$, while that obtained by the on-capillary method was $4.2 \mathrm{mg} / 10 \mathrm{ml}$. These results were comparable to the indicated amount (3-4 mg/10 ml).

\subsubsection{Tap water}

Tap water from Beijing Water Supply Corporation was filtered through a $0.45 \mu \mathrm{m}$ filter membrane before injection

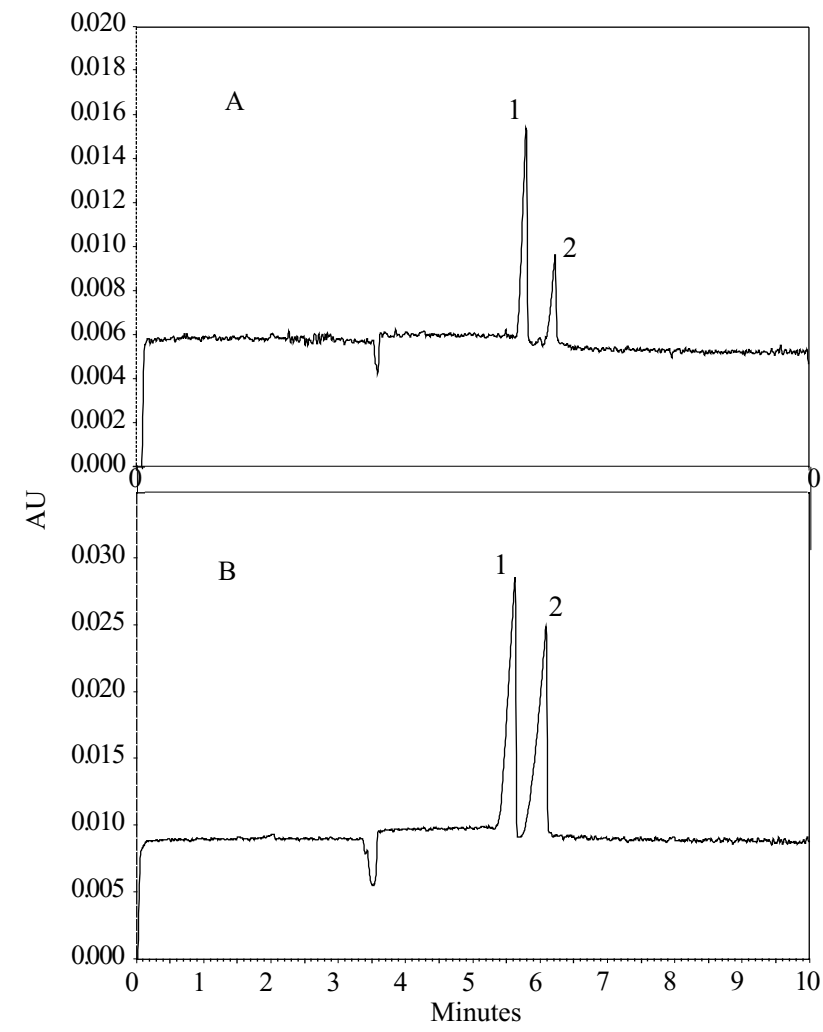

Fig. 7. Electropherograms of zinc gluconate solution. (A) Pre-capillary complexation, hydrodynamic injection $0.5 \mathrm{psi}$ for $5 \mathrm{~s}$. (B) On-capillary complexation, electrokinetic injection for TAR, $t_{\text {inj }}=10 \mathrm{~s}, V_{\text {inj }}=10 \mathrm{kV}$; for metal ions, $t_{\text {inj }}=15 \mathrm{~s}, V_{\mathrm{inj}}=10 \mathrm{kV}$; complexation procedure, $10 \mathrm{kV}$ for $15 \mathrm{~s}$. 1, free TAR; 2, Zn(II). 


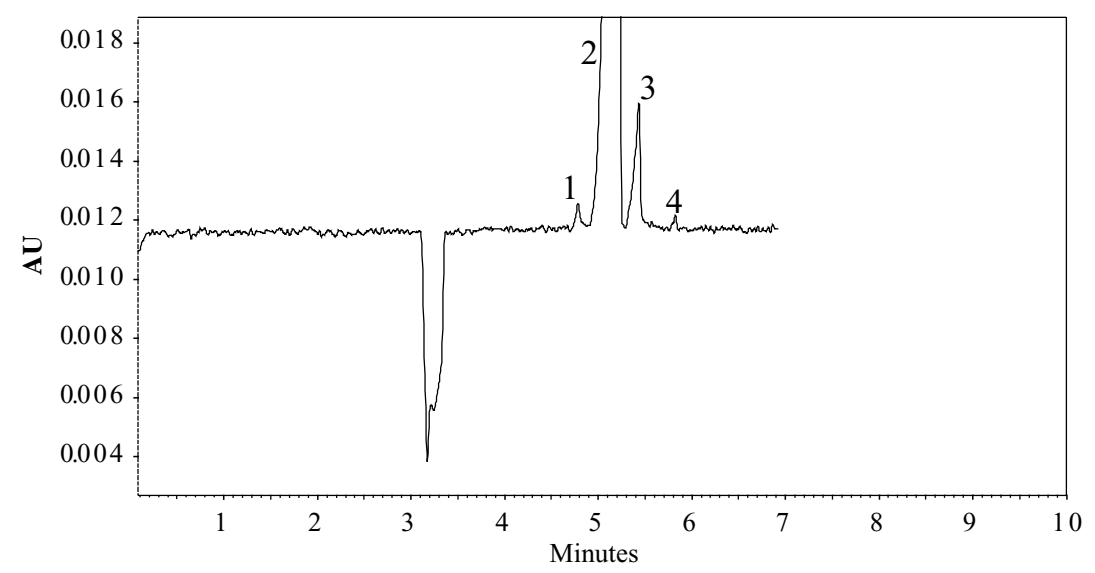

Fig. 8. Electropherograms of tap water. Conditions are the same as in Fig. 7B. 1, Fe(II); 2, free TAR; 3, Zn(II); 4, Ni(II).

Table 4

Results for the determination of metal ions in tap water by CE

\begin{tabular}{lllll}
\hline Metal & $\begin{array}{l}\text { Content } \\
(\mathrm{ng} / \mathrm{ml})\end{array}$ & $\begin{array}{l}\text { Add } \\
(\mathrm{ng} / \mathrm{ml})\end{array}$ & $\begin{array}{l}\text { Found } \\
(\mathrm{ng} / \mathrm{ml})\end{array}$ & $\begin{array}{l}\text { Recovery } \\
(\%)\end{array}$ \\
\hline $\mathrm{Zn}(\mathrm{II})$ & 6.9 & 10 & 17.8 & 109 \\
$\mathrm{Fe}(\mathrm{II})$ & 5.8 & 10 & 16.8 & 110 \\
$\mathrm{Ni}(\mathrm{II})$ & 0 & 10 & 10.1 & 101 \\
$\mathrm{Co}(\mathrm{II})$ & 0 & 10 & 9.3 & 93 \\
\hline
\end{tabular}

into the capillary. No metal ions could be detected when using pre-capillary complexation. For the on-capillary complexation method, $\mathrm{Zn}$ (II), $\mathrm{Ni}$ (II) and $\mathrm{Fe}(\mathrm{II})$ were detectable (Fig. 8). However, the level of Ni(II) was below the LOD. The contents and recoveries of metal ions are shown in Table 4.

\section{Conclusion}

On-capillary complexation is a sensitive and simple method for determination of trace metal ions in aqueous samples, complementing the commonly used pre-capillary or postcolumn complexation. TAR is used as complexing ligand for the determination of $\mathrm{Co}(\mathrm{II}), \mathrm{Zn}(\mathrm{II}), \mathrm{Ni}$ (II) and $\mathrm{Fe}(\mathrm{II})$. The complexation reaction occurs inside the capillary by mixing the zones of ligand and sample during the electrophoretic migration. A 30-fold reduction in detection limits for Co(II), 50-fold reduction for $\mathrm{Zn}$ (II), and 100 -fold reduction for $\mathrm{Ni}$ (II) and $\mathrm{Fe}(\mathrm{II})$ can be achieved, when compared with pre-capillary complexation. The applicability of the methods was demonstrated by the analysis of a pharmaceutical sample and tap water.

\section{Acknowledgements}

The authors wish to thank the financial support of the National Science Fund for Distinguished Young Scholars of China (No. 20125514), National Natural Science Foundation of China (No. 20275043, No. 50273046) and the National High Technology Research and Development Program of China (863 Program) (No. 2001AA630503).

\section{References}

[1] S.C. Jochbson, A.W. Moore, J.M. Ramsey, Anal. Chem. 67 (1995) 2059.

[2] M.J. Spaniak, T. Vo-Dinh, D.L. Stokes, V. Tropina, J.E. Dichens, Talanta 43 (1996) 1889.

[3] F.B. Erim, K. Akýn-Şenel, Fresenius J. Anal. Chem. 362 (1998) 418.

[4] T. Yokoyama, H. Tsuji, T. Kamada, M. Zenki, Anal. Bioanal. Chem. 372 (2002) 832.

[5] A. Weston, P.R. Brown, P. Jandik, W.R. Jones, A.L. Heckenberg, J. Chromatogr. 593 (1992) 289.

[6] N. Shakulashvili, T. Faller, H. Engelhardt, J. Chromatogr. A 895 (2000) 205 .

[7] A.R. Timerbaev, O.P. Semenova, P. Jandik, G.K. Bonn, J. Chromatogr. A 671 (1994) 419.

[8] H. Feng, T. Wang, S.F.Y. Li, Food Chem. 81 (2003) 607.

[9] K.L. Cheng, K. Ueno, T. Imamura (Eds.), CRC Handbook of Organic Analytical Reagents, CRC Press, Boca Raton, FL, 1992, p. 195.

[10] A. Ramesh, Talanta 41 (1994) 355.

[11] R. Saraswati, T.H. Rao, J. Liq. Chromatogr. 16 (1993) 1601.

[12] T. Saitoh, N. Ojima, H. Hoshino, T. Yotsuanagi, Mikrochim. Acta 106 (1992) 91.

[13] B.F. Liu, L.B. Liu, H. Chen, J.K. Cheng, Anal. Chim. Acta 434 (2001) 309

[14] L. Evans, G.E. Collins, J. Chromatogr. A 911 (2001) 127.

[15] M. Wang, F. Qu, J.M. Lin, Chin. J. Environ. Chem. 22 (2003) 236.

[16] F.B. Regan, M.P. Meaney, S.M. Lunte, J. Chromatogr. B 657 (1994) 409.

[17] J. Haumann, K. Bächmann, J. Chromatogr. A 717 (1995) 385. 